Çukurova Üniversitesi Mühendislik Mimarlık Fakültesi Dergisi, 30 (1),79-85 ss., Haziran 2015

Çukurova University Journal of the Faculty of Engineering and Architecture, 30(1), pp.79-85, June 2015

\title{
Çöktürülmüş Kalsiyum Karbonat Üretimi
}

\author{
Özen KILIÇ*1 \\ ${ }^{1}$ Çukurova Üniversitesi, Mühendislik Mimarlık Fakültesi, Maden Mühendisliği Bölümü, Adana
}

Geliş tarihi: 19.02 .2015

Kabul tarihi: 27.02 .2015

\section{Özet}

Yapılan çalışmada, kalsiyum hidroksit çözeltisinden çöktürülmüş kalsiyum karbonat (ÇKK) üretimi incelenmiştir. Uygulanan sistem oldukça basit ve çevre dostu bir karbonizasyon prosesidir. Çalışmada Kalsiyum hidroksit çözeltisine karbondioksit püskürtülerek katkı maddesi kullanılmaksızın kalsiyum karbonat $\left(\mathrm{CaCO}_{3}\right)$ üretimi gerçekleştirilmiştir. Çöktürülmüş kalsiyum karbonat, birbirine yakın tane aralıklarında ve skalenohedral (triangular) kristal şekilli kalsit olarak üretilmiştir. Üretilen sentetik kalsitlerin bileşimi, kristal yapısi/mineralojisi, tane boyutu ve özgül yüzey alanı XRF, XRD, SEM ve mastersizer kullanılarak belirlenmiştir.

Anahtar Kelimeler: Sentetik, Kireçtaşı, Kireç, ÇKK, Karbondioksit

\section{Production of Precipitated Calcium Carbonate}

\begin{abstract}
In this study, the production of precipitated calcium carbonate (PCC) from a suspension of calcium hydroxide was investigated. The applied system is a simple and eco-friendly carbonation process. Carbon dioxide is blown into a suspension of calcium hydroxide, and the resulting calcium carbonate $\left(\mathrm{CaCO}_{3}\right)$ is recovered without any additives. Precipitated calcium carbonate is produced as an uniform particle size and a scalenohedral crystalline shaped calcite. The synthesized calcite was analyzed by XRF, XRD, SEM and mastersizer to identify the content, phase, particle size and specific surface area.
\end{abstract}

Keywords: Synthetic, Limestone, Lime, PCC, Carbon dioxide

\footnotetext{
*Yazışmaların yapılacağı yazar: Özen KILIÇ, Ç.Ü. Müh.Mim. Fak. Maden Mühendisliği Bölümü, Adana. zenkilic@cu.edu.tr
} 


\section{GíRiș}

Kalsiyum, karbon ve oksijen atomlarının kendi aralarında üç farklı yönde düzenlenmesi ile kimyasal formülü $\mathrm{CaCO}_{3}$ olan üç farklı formda kalsiyum karbonat minerali; kalsit, aragonit ve vaterit oluşmaktadır.

Kalsit mikronize boyutlarda öğ̈̈üldükten sonra boya, kağıt, plastik v.b. birçok sektörde beyazlık, ucuzluk ve kazandırdığı özellikler nedeniyle mümkün olduğu kadar fazla kullanılan bir dolgu maddesidir [1]. Çöktürülmüş kalsiyum karbonat, ÇKK (preciptated calcium carbonate, PCC) saflaştırılmış, rafine veya sentetik kalsiyum karbonat $\left(\mathrm{CaCO}_{3}\right)$ anlamına gelmektedir.

Çöktürülmüş ve doğal kalsiyum karbonatın her ikisi içinde en yaygın bilineni hekzagonal yapıdaki kalsittir. Bazı kalsit mineralleri, skalenohedral, rombohedral ve pirizmatik yapıda olabilirler. Nadiren aragonit gibi ayrık veya kümelenmiş iğneli ortorombik kristal yapıda da olabilirler [2] (Şekil 1).

ÇKK dar tane boyut dağglımına ve çok ince başlangıç tane boyutuna sahip olması, yüksek $\mathrm{CaCO}_{3}$ ihtiva etmesi ve düşük safsızlıkları barındırması nedeni ile kağıt-karton üretimi, boya vb sektörlerde tercih edilmektedir. Kalsitin kullanım alanını kimyasal bileşimi ve kristal yapısının yanısıra boyut aralığı da belirlemektedir.

Tane boyutu açısından bakıldığında plastik sektöründe en büyük tane 36-38 $\mu$ m'a kadar izin verildiği halde dolgu kağıt sanayinde 18-20 $\mu \mathrm{m}$ 'u aşması istenmemektedir (Çizelge 1).
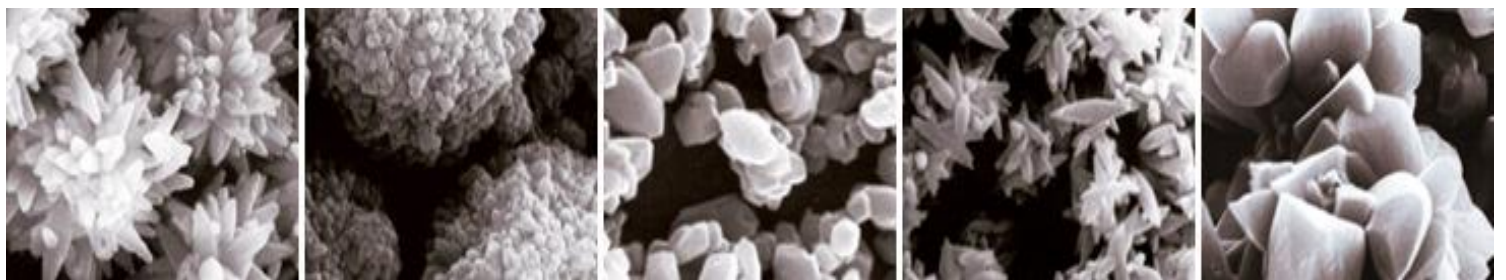

Şekil 1. Farklı şekle sahip PCC tanelerinin SEM (taramalı elektron mikroskop) görüntüleri

Çizelge 1. Kalsitin kullanım alanlarına göre özellikleri [1]

\begin{tabular}{|l|c|c|c|}
\hline Kullanım Yeri & $-2 \mu \mathrm{m}(\%)$ & Ortalama tane, $\mathrm{d}_{50}(\%)$ & En büyük tane, $\mathrm{d}_{97}(\%)$ \\
\hline Boya sektörü (Genel) & $32-34$ & 3,5 & 36 \\
\hline Boya sektörü (İnce ürün) & $55-60$ & 1,6 & 12 \\
\hline Kağıt sektörü (Dolgu) & $42-44$ & 3,0 & $18-20$ \\
\hline Kağıt sektörü (Kaplama) & $80-90$ & 1,0 & $6-8$ \\
\hline Plastik sektörü (Dolgu) & $32-34$ & 3,5 & $18-22$ \\
\hline Plastik sektörü (Kablo diș kaplama) & $42-44$ & 3,2 & 10 \\
\hline Plastik sektörü (Plastik pencere) & 70 & 1,6 & \\
\hline
\end{tabular}

Kalsit (kireçtaşları) her ülkede istenilen saflıkta ve beyazlıkta bulunmamaktadır. PCC prosesi ile kalsiyum karbonat saflığını etkileyen feldispat, silikat mineralleri ve ağır metaller bünyeden uzaklaştırılarak kalsiyum karbonatın saflığı artırılmaktır. ÇKK/PCC üretim maliyeti doğal olarak ögütülmüş kalsite göre daha yüksek olmasına rağmen ürün özellikleri çok daha iyi olduğu için özellikle ABD'de yaygın olarak kullanılmaktadır. PCC'nin dünya genelindeki tüketimi gün geçtikçe artarak 10 milyon ton/yıl seviyelerine ulaşmıştır [3]. Fiyatı içerdiği saflık oranına göre $165-1000$ \$/ton arasinda değişmektedir.

PCC prosesi, farklı şeklilerdeki kristallerin oluşmasına izin vermektir. Tane şekillerinin biçimlendirilmesi; reaksiyon süresi, sicaklık, çalkalanma, basınç, karbondioksit ilave oranı ve post kristalizasyon prosesinin kontrolü ile mümkün 
olmaktadır. Bu șekiller (kümelenmiş iğnemsi, kübik, prizmatik, rombohedral) yığın yoğunluğu, yüzey alanı ve yağ adsorpsiyonu gibi farklı fiziksel özelliklere sahiptir. $\mathrm{Bu}$ da birçok uygulamada doğal kalsiyum karbonatlardan çok daha iyi performans göstermelerini sağlamaktadır.

PCC, kimyasal yöntemlerle üretildiğinden dolayı, tanecik şekli, tanecik boyutu ve tanecik boyut dağılımı kontrol altında tutulmakta ve bu nedenlerden dolayı öğütülmüş kalsiyum karbonata (GCC) göre avantajları bulunmaktadır. Doğal kalsiyum karbonatın kimyasal çöktürme işlemi sonucunda kazanmış olduğu bu yapı, malzemeye, çarpma dayanımı, parlaklık, opaklık gibi artı özellikler kazandırmaktadır.

\section{2. ÇÖKTÜRÜLMÜŞ KALSIYYUM KARBONAT ÜRETIMI}

Sentetik (çöktürülmüş) kalsiyum karbonat üretiminin değişik yöntemleri olmasına rağmen en çok tercih edileni, saf kireçtaşlarının kalsinasyonu ile üretilendir [4-8]. Özellikle ABD'de uygulanan yönteme göre silisi düşük kireçtaşları yakılarak (kalsine edilerek) önce $\mathrm{CaO}$ elde edilir ve suyla karıştırılarak oluşan kireç sütünden bir reaktör içerisinde $\mathrm{CO}_{2}$ gazı basınç altında (bazı kimyasallar eklenerek) sisteme verilerek tane büyüklüğü (1-3 $\mu \mathrm{m}$ boyutlarında) ve kristal şekli kontrol edilebilen suni ve saf kalsit kristalleri oluşturulması yoluna gidilmektedir. Proses kısaca kalsinasyon (1), hidratasyon (2) ve çöktürme (3) aşamalarından oluşmaktadır.

Kireçtaşı kireç firınlarında $950-1000^{\circ} \mathrm{C}$ [9] sicaklıklarda kalsine edilerek imal edilmektedir (eşitlik 1). Kireç $(\mathrm{CaO})$ su ile hidrat haline getirilmektedir ve kalsiyum hidroksit çamuru elde edilmektedir (eşitlik 2). $\mathrm{Bu}$ çamura $\mathrm{CO}_{2}$ gazı enjekte edilir, $\mathrm{CO}_{2}$ gazı kalsiyum hidroksit ile reaksiyona girer ve bunun sonucunda çöken ürün kalsiyum karbonat olarak elde edilmektedir (eşitlik 3).

$\mathrm{CaCO}_{3(\mathrm{k})}+\mathrm{ISI} \rightarrow \mathrm{CaO}_{(\mathrm{k})}+\mathrm{CO}_{2} \uparrow_{(\mathrm{g})}$

$\mathrm{CaO}_{(\mathrm{k})}+\mathrm{H}_{2} \mathrm{O} \rightarrow \mathrm{Ca}(\mathrm{OH})_{2 \text { (suda) }}$

$\mathrm{Ca}(\mathrm{OH})_{2 \text { (suda) }}+\mathrm{CO}_{2(\mathrm{~g})} \rightarrow \mathrm{CaCO}_{3} \downarrow_{(\mathrm{k})}+\mathrm{H}_{2} \mathrm{O}$
Çöktürülen ürün, filtre edilir, yıkanır ve kağıt sektörünün hizmetine genellikle süspansiyon halinde sunulur. $\mathrm{Bu}$ yöntemde, $\mathrm{CaCO}_{3}$ aragonit formundadır ve GCC'ye nazaran saflığı daha yüksektir. Doğal kalsiyum karbonatın kimyasal çöktürme işlemi sonucunda kazanmış olduğu bu yapı ve yüksek yüzey alanı sayesinde, kağıdın opaklığı ve parlaklığı, düşük hacimlerde ÇKK kullanımı ile bile artmakta, yine bununla kaplama makinelerinin sorunsuz bir şekilde çalışması sağlanmaktadır.

\section{MATERYAL VE YÖNTEM}

Çöktürülmüş kalsiyum karbonat üretmek için Çelemli, Adana yöresi kireçtaşlarından elde edilen kireç örnekleri kullanılmıştır. Bölge kireçtaşları oldukça zengin kireçtaşı rezervine sahiptir.

- Kireçtaşlarının ve üretilen kalsit örneklerinin kimyasal analizleri XRF (Siemens SRS 300 X-ray Fluoresans Spectometer) kullanılarak gerçekleştirilmiştir.

- Üretilen kalsitlerin mineralojik incelemeleri XRD (Rigaku Minflexs 2) analizi ile yapılmıştır.

- SEM analizleri örnekler altınla kaplandıktan sonra Zeiss Evo 60 EP-SEM ve buna bağlı görüntü analiz sistemi ile incelenip fotoğraflanmıştır.

- Örneklerin özgül yüzey alanı ve tane boyutu dağılımı Malvern Instruments Mastersizer 2000 Ver. 5.60 ile belirlenmiştir.

Katı yoğunluğu \%2,5'un altında olduğu şartlarda aragonit minerali $\left(\mathrm{CaCO}_{3}\right)$ oluşmaktadır [6]. $\mathrm{Bu}$ nedenle, deneylerde kat1 yoğunluğu \%2,5 olarak alınmıştır. Karışım sıcaklığı $50^{\circ} \mathrm{C}$ olarak sabit tutulmuştur. Ortam basıncı deneyler sırasında 1 bar olarak sabit tutulmuş artırılmamıştır. Karbondioksitin $(\% 99,9)$ ortama beslenmesi 300, 500, 750 ve $1000 \mathrm{ml} / \mathrm{dk}$ ve karıştırıcının sulu karışımı karıştırma hızları 400, 500, 600 ve 700 dev/dk olacak şekilde farklı karıştırma süreleri uygulanmıştır. Deney başlangıcında karışımın-ortamın pH'sı tüm deneylerde 12,40 olurken PCC oluşumuna bağlı olarak deney sonunda $\mathrm{pH}$ 7-12,10 arasında değişim göstermiştir. 
PCC üretim deneyleri Çizelge 2'de özellikleri belirtilen aralıklarda oluşturulan ortam şartlarında gerçekleştirilmiş, PCC üretimi için alternatif koşullar araştırılmıştır.

Çizelge 2. Çöktürülmüş kalsiyum karbonat üretimi için uygulanan deney şartları

\begin{tabular}{|c|c|}
\hline $\begin{array}{c}\text { Örnek } \\
\text { Ad1 }\end{array}$ & Deney Şartları \\
\hline 1 & $\begin{array}{l}\text { Başlangıç pH: } 12,40 \text { Bitiş pH: } 8,950 \\
\text { Karıştırma hızı: } 500 \mathrm{dev} / \mathrm{dk} \\
\text { Süre: } 16 \mathrm{dk} \\
\mathrm{CO}_{2}: 1 \text { bar- } 1000 \mathrm{ml} / \mathrm{dk}\end{array}$ \\
\hline 2 & $\begin{array}{l}\text { Başlangıç pH: } 12,40 \text { Bitiş pH: 7,970 } \\
\text { Karıştırma hızı: } 600 \mathrm{dev} / \mathrm{dk} \\
\text { Süre: } 16 \mathrm{dk} \\
\mathrm{CO}_{2}: 1 \text { bar- } 1000 \mathrm{ml} / \mathrm{dk}\end{array}$ \\
\hline 3 & $\begin{array}{l}\text { Başlangıç pH: } 12,40 \text { Bitiş pH: } 8,05 \\
\text { Karıştırma hızı: } 700 \mathrm{dev} / \mathrm{dk} \\
\text { Süre: } 16 \mathrm{dk} \\
\mathrm{CO}_{2}: 1 \text { bar-1000 ml/dk }\end{array}$ \\
\hline 4 & $\begin{array}{l}\text { Başlangıç pH: } 12,40 \text { Bitiş pH: 7,02 } \\
\text { Karıştırma hızı: } 500 \mathrm{dev} / \mathrm{dk} \\
\text { Süre: } 50 \mathrm{dk} \\
\mathrm{CO}_{2}: 1 \text { bar-300 ml/dk }\end{array}$ \\
\hline 5 & $\begin{array}{l}\text { Başlangıç pH: } 12,40 \text { Bitiş pH: } 12,51 \\
\text { Karıştırma hızı: } 500 \text { dev/dk } \\
\text { Süre: } 3 \text { dk } 18 \mathrm{~s} \\
\mathrm{CO}_{2}: 1 \text { bar- } 500 \mathrm{ml} / \mathrm{dk}\end{array}$ \\
\hline 6 & $\begin{array}{l}\text { Başlangıç pH: } 12,40 \text { Bitiş pH: } 12,28 \\
\text { Karıştırma hızı: } 500 \mathrm{dev} / \mathrm{dk} \\
\text { Süre: } 2 \mathrm{dk} 30 \mathrm{~s} \\
\mathrm{CO}_{2}: 1 \text { bar-750 ml/dk }\end{array}$ \\
\hline
\end{tabular}

\section{BULGULAR}

Çelemli, Adana yöresi kireçtaşlarına uygulanan kimyasal analiz sonuçlarının 1şı̆̆ında kireçtaşlarının \% $\mathrm{CaCO}_{3}$ oranının \%97'dan fazla olduğu görülmüş ve safsızlık oranının düşük olması nedeniyle iyi kalite çöktürülmüş kalsiyum karbonat üretiminin mümkün olabileceği kanısı oluşmuştur (Çizelge 3).

Çizelge 2'de belirtilen deney şartlarında elde edilen ürünlerin kimyasal analiz sonuçları Çizelge 3'de verilmiştir. Örneklerin kimyasal analiz sonuçları incelendiğinde \%99 saflıkta PCC elde edildiği görülmüş ve uygulanan şartların (Çizelge 2) çöktürülmüş kalsiyum karbonat üretimi için uygun olduğu anlaşıllmıştır.

Üretilen PCC'lere yapılan mineralojik analizler incelendiğinde örneklerin hepsinin kalsit kristallerinden yapılı olduğu belirlenmiştir (Şekil 2,3). Kalsitlerin trigonal kristal şekline sahip skalenohedral tipte olduğu görülmüştür.

Örneklerin ince taneli olması ve ölçülen yüzey alanı analizi değerlerinin $<20 \quad \mathrm{~m}^{2} / \mathrm{g}$ olması nedeniyle üretilen PCC'lerin piyasanın istediği özelliklerde olduğu anlaşılmıştır (Çizelge 4).

Çizelge 3. Üretilen örneklerin kimyasal analiz sonuçları (\%)

\begin{tabular}{|c|c|c|c|c|c|c|}
\hline Örnek & $\mathrm{Al}_{2} \mathrm{O}_{3}$ & $\mathrm{Cr}_{2} \mathrm{O}_{3}$ & $\mathrm{Fe}_{2} \mathrm{O}_{3}$ & $\mathrm{SO}_{3}$ & $\mathrm{MgCO}_{3}$ & $\mathrm{CaCO}_{3}$ \\
\hline 1 & 0,18 & 0,01 & 0,10 & 0,11 & 0,36 & 99,24 \\
\hline 2 & 0,11 & 0,01 & 0,08 & 0,09 & 0,42 & 99,56 \\
\hline 3 & 0,19 & 0,01 & 0,07 & 0,13 & 0,15 & 99,45 \\
\hline 4 & 0,18 & 0,01 & 0,07 & 0,10 & 0,23 & 99,41 \\
\hline 5 & 0,19 & 0,01 & 0,07 & 0,07 & 0,14 & 99,52 \\
\hline 6 & 0,15 & 0,01 & 0,06 & 0,11 & 0,15 & 99,55 \\
\hline
\end{tabular}

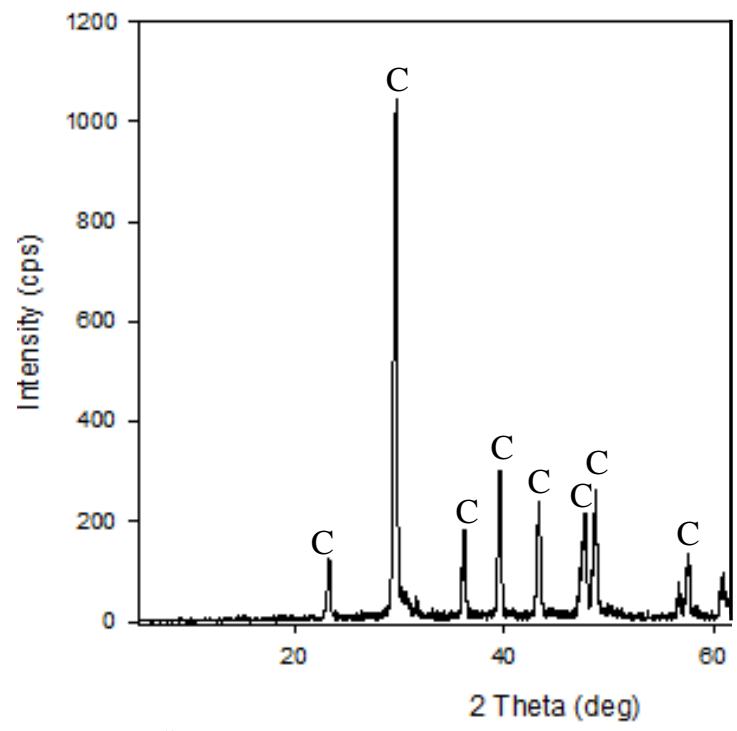

Şekil 2. Üretilen PCC örneğinin XRD paterni (C: Kalsit) 


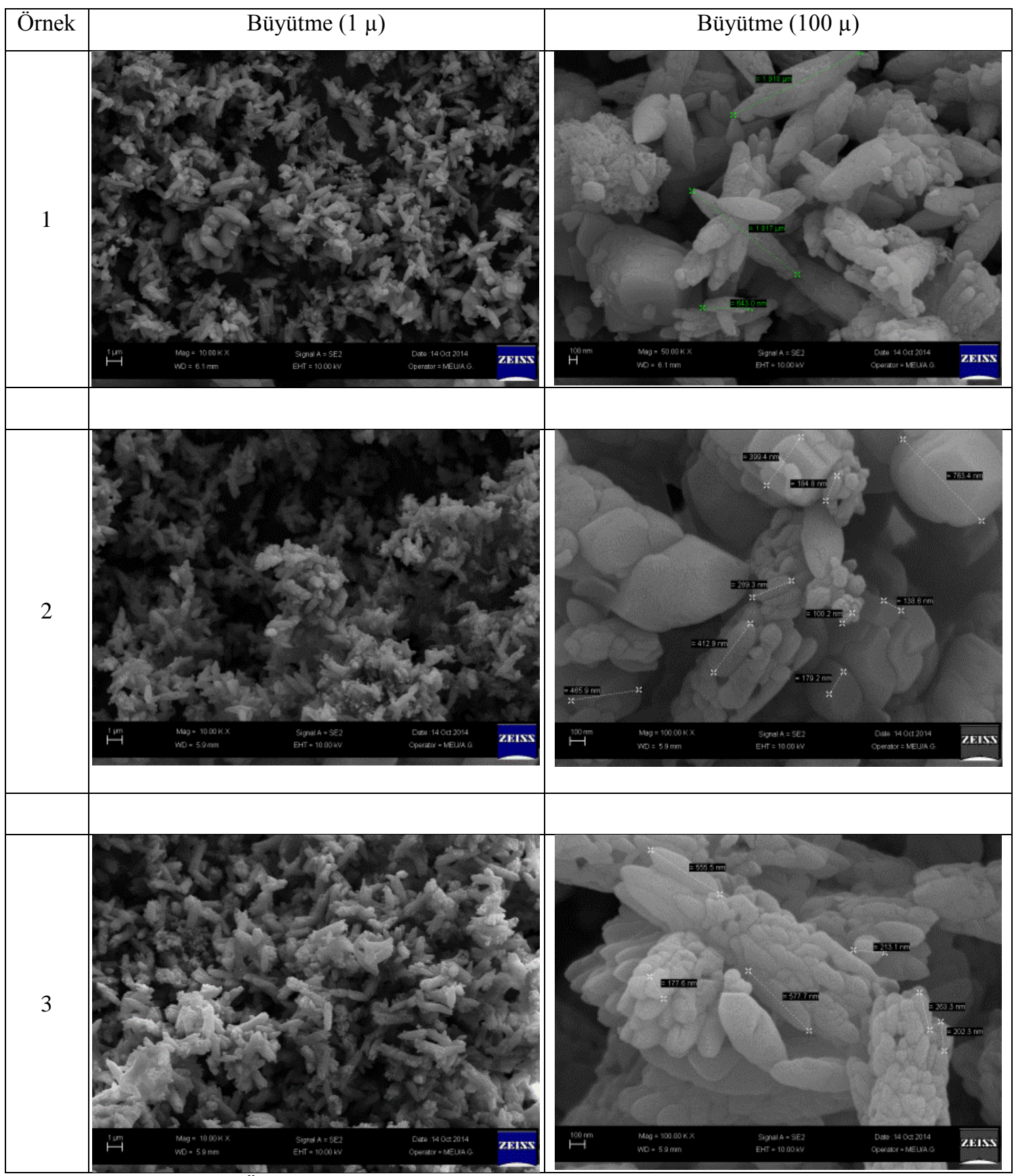

Şekil 2. Üretilen örneklerin farklı büyütmelerde SEM analizi görüntüleri 


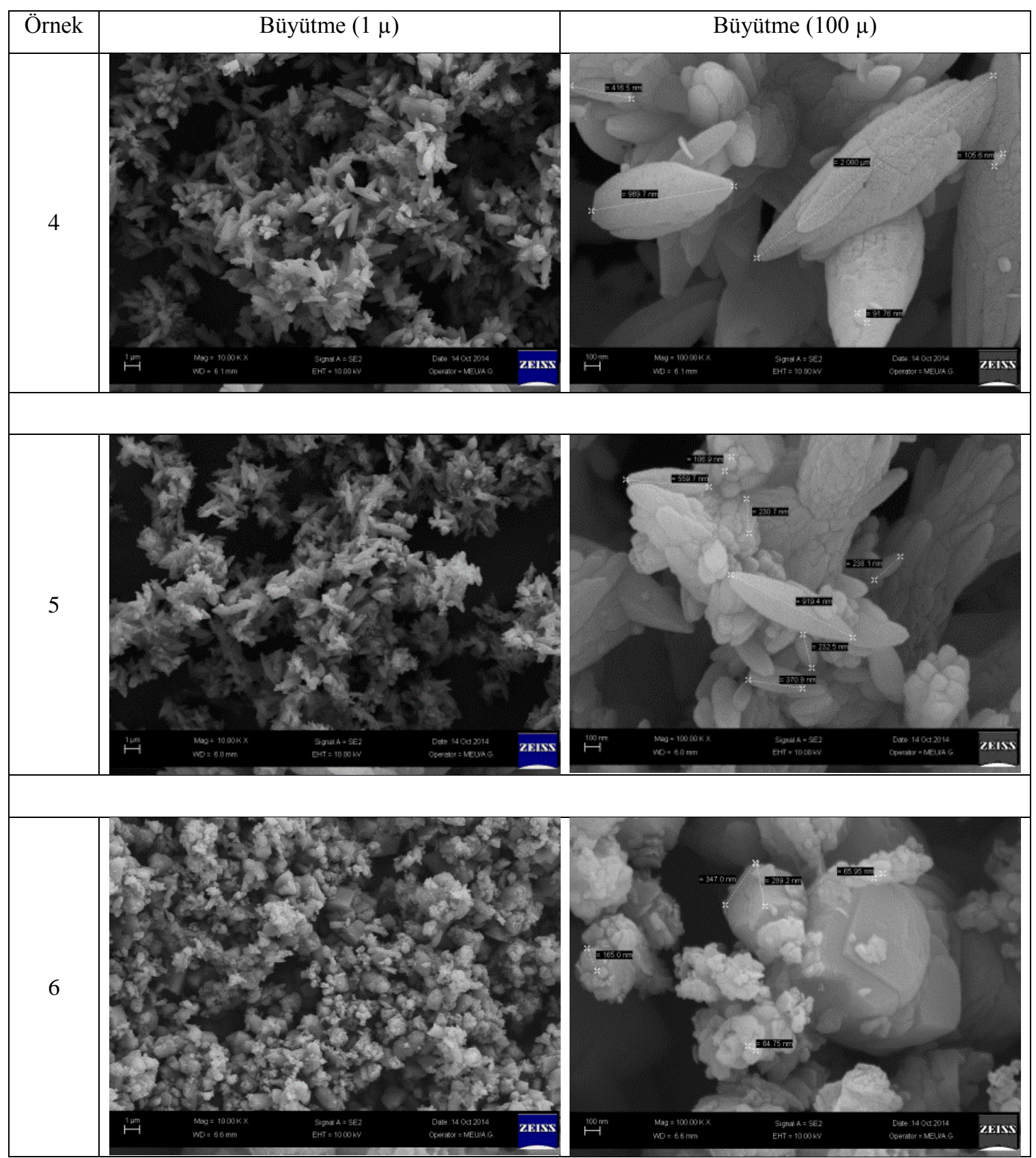

Şekil 3. Üretilen örneklerin farklı büyütmelerde SEM analizi görüntüleri, devamı

\section{SONUC}

Örneklerin kimyasal analiz sonuçları incelendiğinde uygulanan proses ve şartlarda \%99 saflıkta PCC üretilebildiği anlaşılmıştır.
Üretilen PCC'lere yapılan mineralojik analizler ve SEM analizleri incelendiğinde örneklerin hepsinin kalsit kristallerinden yapılı olduğu tespit edilmiştir. Örneklerin ölçülen yüzey alanı analizi değerlerinin $<20 \mathrm{~m}^{2} / \mathrm{g}$ olması nedeniyle üretilen PCC'lerin 
kağıt üretimi için kullanımının uygun olacağı ve piyasadan talep görebilecek özelliklerde olduğu anlaşılmıştır.

\section{KATKI BELİRTME}

Yazar çalışmaya sağladığı destekten dolayı ÇÜBAP (Çukurova Üniversitesi Rektörlüğü Bilimsel Araştırma Projeleri Koordinasyon Birimi, MMF2011BAP12)'a teşekkür eder.

\section{KAYNAKLAR}

1. DPT, 2001. Sekizinci Beş Yıllık Kalkınma Plan1, Madencilik Özel İhtisas Komisyonu Raporu, 2618-ÖİK: 629, Ankara.

2. www.adacal.com.tr

3. Mineset Partner Report, 2002. The Global Outlook for Extender and Filler Minerals in Paper, Mineset Partners LLC, Rockaway.

4. Teir, S., Eloneva, S., Fogelholm, C. J., Zevenhoven, R., 2007. Dissolution of Steelmaking Slags in Acetic Acid for Precipitated Calcium Carbonate Production Energy, 32(4):528-539.

5. Ryu, M., You, K., Ahn, J., Kim, H., 2007. Effect of the $\mathrm{pH}$ and Basic Additives on the Precipitation of Calcium Carbonate during Carbonation Reaction, Resources Processing, Volume 54, Pages 14-18.

6. Sung-Tsuen, L., Robert M., 2008. Precipitated Calcium Carbonate, United States Patent No 7361324.

7. Jasra, R.V., Oza M., Somanı S., Chunnawala, R., Sheth V., Thakkar, V., Badheka M., Ayyer J., Patel B., 2004. Process for Generation of Precipitated Calcium Carbonate from Calcium Carbonate Rich Industrial By-Product United States Patent No 6790424.

8. Thriveni, T., Um, N., Nam, S. Y., Ahn, Y. J., Han, C., Ahn, J., W., 2014. Factors Affecting the Crystal Growth of Scalenohedral Calcite by a Carbonation Process, Journal of the Korean Ceramic Society, 51(2), 107-114.

9. Kılıı, Ö., 2005. Klasik Eberhart Tipi Kireç Fırınları ile Paralel Akışlı Maerz Fırınlarındaki Kalsinasyon Parametrelerinin Karşılaştırılması ve Çukurova Bölgesi Kireçtaşları Üzerine
Uygulamalar, Ç.Ü. Fen Bilimleri Enstitüsü Maden Mühendisliği Anabilim Dalı Doktora Tezi, s 171, Adana. 
